\title{
Al-Fe-U (Aluminum-Iron-Uranium)
}

\section{Raghavan}

The experimental data on this ternary system were updated by [2006Rag], who presented an isothermal section at $850{ }^{\circ} \mathrm{C}$ from the work of [2005Gon]. Recently, [2010Mes] determined a liquidus projection for Al-rich alloys.

\section{Binary Phases}

In the $\mathrm{Fe}-\mathrm{Al}$ phase diagram [Massalski2], the solid solution $\gamma$ based on face-centered cubic (fcc) Fe is restricted by a loop. The solid solution based on the body-centered cubic (bcc) $\mathrm{Fe}(\alpha)$ exists in both the disordered $(A 2)$ and the ordered $\left(B 2\right.$ and $\left.\mathrm{DO}_{3}\right)$ forms. Apart from the high temperature phase $\varepsilon\left(D 8_{2}, \mathrm{Cu}_{5} \mathrm{Zn}_{8}\right.$-type cubic), there are three intermediate phases in the system with restricted ranges of homogeneity: $\mathrm{FeAl}_{2}$ (triclinic), $\mathrm{Fe}_{2} \mathrm{Al}_{5}$ (orthorhombic) and $\mathrm{Fe}_{4} \mathrm{Al}_{13}$ (monoclinic). In the $\mathrm{Al}-\mathrm{U}$ system [Massalski2], the intermediate phases are: $\mathrm{UAl}_{2}\left(C 15, \mathrm{MgCu}_{2}\right.$-type cubic), $\mathrm{UAl}_{3}\left(L_{2}, \mathrm{AuCu}_{3}\right.$-type cubic) and $\mathrm{U}_{0.9} \mathrm{Al}_{4}\left(D 1_{b}\right.$-type orthorhombic). The Fe-U phase diagram [Massalski2] has two compounds: $\mathrm{Fe}_{2} \mathrm{U}\left(C 15, \mathrm{MgCu}_{2}\right.$-cubic $)$ and $\mathrm{FeU}_{6}\left(D 2_{c}\right.$, $\mathrm{MnU}_{6}$-type tetragonal).

\section{Ternary Phases}

The structural characteristics of seven known ternary phases of this system were summarized by [2006Rag]. All these phases are present in the isothermal section at $850{ }^{\circ} \mathrm{C}$ [2005Gon]. In the Al-rich alloys reviewed here, $\mathrm{UFe}_{2} \mathrm{Al}_{10}$ (denoted $\tau_{1}$ by [2006Rag]) ( $\mathrm{YbFe}_{2} \mathrm{Al}_{10}$-type orthorhombic) is present. In addition, a new Al-rich compound $\mathrm{U}_{2} \mathrm{FeAl}_{20}$ (denoted $\tau$ here) is present (not listed by [2006Rag]). This phase was reported by [2008Mes] to be tetragonal, space group $I \overline{4} 2 \mathrm{~m}$ with lattice parameters $a=1.24138 \mathrm{~nm}$ and $c=1.03014 \mathrm{~nm}$.

\section{Liquidus Projection}

With starting metals of $99.99 \% \mathrm{Al}, 99.99 \% \mathrm{Fe}$ and 99.95\% U, [2010Mes] arc-melted under Ar atm six ternary alloys containing 80 to 92 at.\% Al. The phase equilibria were studied with differential scanning calorimetry, x-ray powder diffraction, optical and scanning electron microscopy and energy dispersive $\mathrm{x}$-ray analysis. The liquidus surface constructed by [2010Mes] for Al-rich alloys is shown in Fig. 1. $\mathrm{UFe}_{2} \mathrm{Al}_{10}\left(\tau_{1}\right)$ forms through the ternary peritectic reaction $\mathrm{P}_{1}: \mathrm{L}+\mathrm{UAl}_{3}+\mathrm{Fe}_{4} \mathrm{Al}_{13} \leftrightarrow \tau_{1}$ between 850 and $1157{ }^{\circ} \mathrm{C}$. $\mathrm{U}_{2} \mathrm{FeAl}_{20}(\tau)$ forms through the reaction

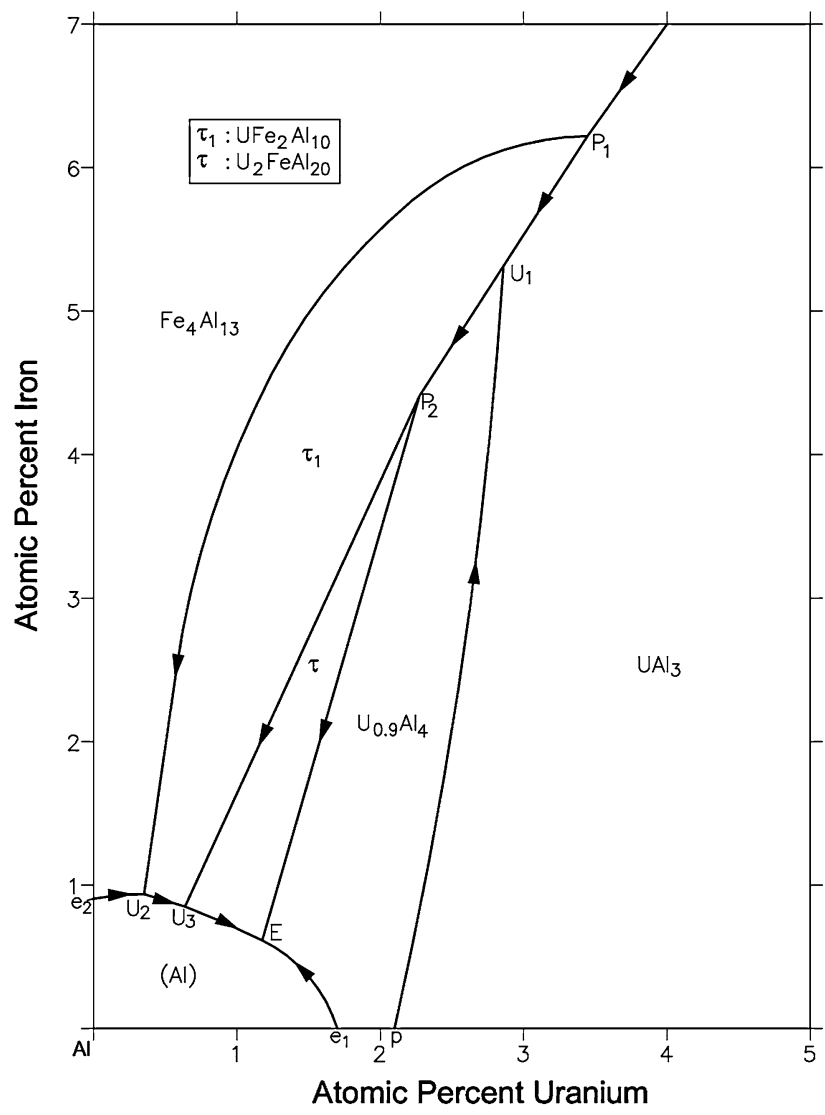

Fig. 1 Al-Fe-U tentative liquidus projection for Al-rich alloys [2010Mes]

$\mathrm{P}_{2}: \mathrm{L}+\mathrm{U}_{0.9} \mathrm{Al}_{4}+\tau_{1} \leftrightarrow \tau$ at $639{ }^{\circ} \mathrm{C}$. Keeping in view the binary eutectic reactions at the Al-end in the Al-Fe and Al-U systems, the final solidification is tentatively shown in Fig. 1 as a ternary eutectic reaction E.

\section{References}

2005Gon: A. Goncalves and $H$. Noel, Isothermal Section at $850^{\circ} \mathrm{C}$ of the U-Fe-Al Ternary System, Intermetallics, 2005, 13, p 580-585

2006Rag: V. Raghavan, Al-Fe-U (Aluminum-Iron-Uranium), J. Phase Equilib. Diffus., 2006, 27(3), p 281-282

2008Mes: L. Meshi, A. Munitz, and M. Talianker, Determination of the Structure of a New Tetragonal phase $\mathrm{U}_{2} \mathrm{FeAl}_{20}, J$. Alloys Compd., 2008, 460, p 196-200

2010Mes: L. Meshi and A. Munitz, Liquidus Projection of Al-Rich Corner of the Ternary Al-Fe-U System, Intermetallics, 2010, 18, p 2119-2123 